\title{
Documentos
}

DISCURSO DEL PRIMER MINISTRO DE JAMAICA, SEÑOR MICHAEL MANLEY, EN LA XIV REUNION DE LA ASAMBLEA DE GOBERNADORES DEL BANCO INTERANIERICANO DE DESARROLLO

Señor Presidente,

Su Excelencia, Gobernador General Interino, Señor Herbert Duffus,

Señor Presidente del Banco Interamericano de Desarrollo,

Señores Gobernadores y' Gobernadores Suplentes,

Señores Gobernadores Suplentes y Consejeros Temporales,

Distinguidos Invitados, Damas y Caballeros:

Es mi deseo asociar el pueblo de Jamaica, su Gobierno y' mi persona a la cordial bienvenida que ha dispensado a todos nuestros visitantes el Presidente de la Asamblea y nuestro Viceprimer Ministro, señor David Coore.

Por muchas razones, esta Reunión Anual del Banco Interamericano es un acontecimiento de importancia especial para Jamaica. Primero, los jamaicanos nos sentimos honrados de poder acoger en nuestro medio a tan nutrida reunión de distinguidos representantes de las principales instituciones crediticias del mundo. Nos satisface, en particular, que esta oportunidad se haya presentado tan corto tiempo después de habernos asociado al Banco, $Y$, en nombre de nuestros hermanos del Caribe, acepto este honor como señal de que se reconoce así el papel que las naciones más pequeñas de habla inglesa pueden desempeñar, y desempeñarán, en la promoción de un futuro mejor para los pueblos del hemisferio, mediante la cooperación, la amistad y la asistencia mutua. Segundo, esta reunión, en este momento en que tratamos diligentemente de establecer relaciones estrechas con nuestros hermanos del "Tercer Mundo", manteniendo a la vez nuestras amistades tradicionales, ofrece la oportunidad de renovar contactos y de establecex amistades de carácter personal. Tercero, este acontecimiento nos da a todos ocasión para analizar las similitudes $y$ diferencias en los problemas del desarrollo que encaran los países del hemisferio en general y, en especial, para apreciar en mayor medida las aspiraciones, objetivos, recursos y estrategias del desarrollo de Jamaica.

Los jamaicanos consideramos que el individuo es el único foco del esfuerzo de desarrollo. Creemos que la meta del desarrollo debe ser mejorar las condi- 
ciones físicas, mentales, espirituales y sociales del pueblo. Creemos que el esfuerzo más fructifero es el del propio pueblo y que la clave de un progxeso real es el aprovechamiento de los recursos propios.

En función de estas convicciones, nuestros objetivos concretos inmediatos son mejorar la capacidad del pueblo de Jamaica para satisfacer sus necesidades materiales mediante la aplicación de su propio esfuerzo creativo a los xecursos físicos disponibles. Para tener la certeza de que habrá voluntad de empeñar este esfuerzo, pensamos que debemos crear una sociedad justa en la que el individuo no esté sujeto a explotación y privación económicas, opxesión política y religiosa y discriminación por razones culturales o raciales. Es decir, debemos instituir y mantener una estructura social en que pueda haber interacción humana racional y provechosa y en la que el individuo pueda sentir la seguridad personal que se deriva de la libertad y la libertad de pensamiento $y$ acción que sólo es posible cuando los hombres se sienten seguros.

El pueblo y el Gobierno de Jamaica no se aferaan a ninguna opinión dogmática predeterminada respecto a los sistemas políticos y económicos que puedan coadyuvar a la rcalización de estos objetivos. Consideramos que el problema no radica en elegir entre ideologias formuladas en otras épocas y lugares en función de otras condiciones, sino en idear con nuestra propia inventiva, los sistemas más acordes con nuestras necesidades. En consecuencia, nuestras soluciones deben concebirse a la luz de las condiciones históricas, sociales, físicas y culturales que determinan el contexto peculiarmente jamaicano en que deba forjarse nuestro destino.

No tenemos ningún compromiso ideológico dogmático en lo político y' económico que no sea nuestra devoción a la justicia social mediante la igualdad en el contexto de libertad. Sin embargo, estudiando el contexto peculiarmente jamaicano, hemos llegado a una hipótesis viable que es el marco de referencia conforme al cual se ha determinado nuestra estrategia de desarrollo y en función del cual debe comprendérsela. El sistema político más acorde con nuestras necesidades es la democracia parlamentaria multipartidaria con un gobierno elegido por la mayoría en elecciones libres. Somos partidarios de un sistema económico mixto. El pueblo, en la acepción de las personas particulares, puede poseer, controlar y usar recursos conforme a los arreglos privados de producción y comercialización. El pueblo, por conducto del Estado, puede poseer, controlar y usar los recursos conforme a los mecanismos públicos. Finalmente, el pueblo puede poseer recursos mediante una combinación del esfuerzo de los sectores público y privado en empresas mixtas. No tenemos un concepto predeterminado de la forma empresarial preferida. Creemos que en la variedad todos pueden coadyuvar al logro de nuestros objetivos. Nuestro enfoque es pragmático, pero deliberado y nuestra hipótesis de trabajo es que el desarrollo debe empezar donde estamos y con lo que tenemos.

¿Dónde estamos como pueblo, como sociedad y como economía? Como pueblo recién independiente estamos todavía en el proceso de plasmar nuestra identidad, 
una condensación de las esencias combinadas de nuestro variado y rico patrimonio cultural.

Como sociedad todavía vamos a tientas, por entre las heredadas contradicciones de nuestro pasado colonial hacia nuestro ideal de justicia y libertad para todos.

Como economía hemos experimentado un rápido crecimiento y aprendido por esa experiencia que si la producción no se encamina hacia el bien de nuestros pueblos, si el sistema de relaciones económicas no se depura de los últimos vestigios de la explotación humana institucionalizada y si el ser humano no es el recurso fundamental, el crecimiento económico acelerado, por sí solo, no resolverá Ios problemas de la pobreza, el desempleo y la desigual distribución del ingreso.

Nuestro principal recurso es el pueblo. Nuestro pueblo industrioso y volurtarioso se ha ganado una envidiable reputación por su trabajo en muchos países a donde ha ido a vivir o a trabajar por contrato. Nuestra superficie de tierra es poco más de un acre por habitante para casi dos millones de habitantes. La parte cultivable no pasa del $50 \%$ del total. Tenemos abundancia de bauxita, pero no debemos olvidar que éste es uno de los minerales más abundantes en la corteza terrestre. Aunque no poseemos fuentes de energia como el petróleo, el carbón o la fuerza hidráulica o nuclear, la fuerza de voluntad de nuestro pueblo no es insuficiente. Tenemos hermosos paisajes, buenas playas y un clima cálido y agradable.

Aunque la principal fuente de capital para la explotación de estos recursos para el desarrollo agxicola e industrial ha sido el ahorro interno, éste no ha sido suficiente por causa del círculo vicioso del "bajo ingreso/bajo ahorro".

Le estrategia jamaicana de desarrollo se apoya en la importancia del pueblo como foco de ese desarrollo y recurso principal. Creemos que la confianza en nosotros mismos es el único camino hacia la independencia verdadera. Creemos que la eficacia con que el pueblo puede contribuir al mejoramiento de su bienestar dependerá, primero, del grado en que pueda motivarse al pueblo para que se inicie y participe en una actividad productiva; segundo, de la preparación adecuada del pueblo para participar en tal actividad mediante la educación y la capacitación encaminados a la adquisición de pericias y capacidades profesionales; tercero, de la disponibilidad de oportunidades suficientes para participar en actividades productivas; cuarto, de la disponibilidad de recursos complementarios como herramientas, máquinas, edificios, tierras, materias primas y combustibles para sustentar el esfuerzo humano; quinto, de las relaciones mutuaniente beneficiosas con otros pueblos, y, sexto, de una selección adecuada de la producción.

Para dar una idea más clara de nuestro enfoque, me referiré brevemente a esas determinantes de la capacidad del pueblo para mejorar su situación. La motivación del pueblo para actuar por sí mismo en la labor de emprender el esfuerzo de producción y participar en él dependerá de la certeza con que pueda esperar gozar del fruto de su trabajo para satisfacer las necesidades que y'a existen.

La modalidad de relaciones explotadoras característica de la sociedad jamaicana posterior a 1838, lejos de conducir a la certeza de la esperanza del beneficio, 


\section{ESTUDIOS INTERNAGIONALES}

sirvió sólo para reforzar la idea de que el trabajo es inoperante como medio de mejoramiento personal $\mathrm{y}$ que la propiedad es el único camino. Nuestra estrategia requiere que el trabajador reciba una justa remuneración por su trabajo, por un lado para restablecer la fe en el trabajo $y$, por el otro, porque es justo que así sea. Además, el trabajador debe tener la oportunidad de participar en la propiedad del capital $y$ en la adopción de las decisiones que afectan a su parte de la producción.

Esto ha entrañado el establecimiento, a partir de este año, de un sistema educativo gratuito en los niveles primario, secundario $y$ universitario. El ingreso en este sistema gratuito se hará exclusivamente en función del mérito y los beneficiarios deberán prestar dos años de servicio nacional al terminar su educación. En esencia, este servicio se concentrapá en el sistema educativo, a fin de ampliar aceleradamente su alcance.

Sabemos que aunque las empresas privadas y el Gobierno no están en condiciones de ofrecer todavía oportunidades adecuadas para que el pueblo participe en las actividades productivas, un pueblo que confía en sus propias fuerzas puede crear con ayuda y orientación esas oportunidades. La educación y el adiestramiento pueden ayudarle a identificar $y^{\prime}$ aprovechar esas oportunidades. Por lo tanto, me complace decir que recientemente nos hemos embarcado en un programa en gran escala para salir del dilema del desempleo que coexiste con la escasez de mano de obra. De acuerdo con la idea de que una economía mixta es más beneficiosa para el pueblo, el Gobierno, a más de fomentar actividades empresarias privadas, participará en empresas mixtas con intereses privados y en la producción directa, a fin de asegurar al pueblo oportunidades de trabajo productivo. Los recursos financieros son los medios con que se moviliza la mayoría de los recursos complementarios para fructificar el esfuerzo humano. Nuestra estrategia es aumentar el ahorro interno pues así se facilita el logro paralelo de nuestro objetivo de obtener un mayor control sobre la economía nacional. No obstante, hemos usado $y$ continuaremos necesitando recursos financieros externos de fuentes privadas $y^{r}$ públicas. El capital privado que ingxesa al país de acuerdo con nuestras políticas nacionales y se pone al servicio de los intereses nacionales es bien acogido, $y$ garantizamos el derecho de repatriar utilidades razonables y la depreciación acumulada al terminar la inversión. Respecto del capital prestado, la solvencia de Jamaica es insospechable.

Aunque exaltamos las virtudes de la movilización de los propios recursos sabemos que la cooperación con otras naciones puede redundar en considerable beneficio mutuo. Nos hemos asociado, por ello, al movimiento de integración económica del Caribe. Las tendencias de la oferta y la demanda mundiales, la cambiante relación del intercambio y la estructura de los mercados internacionales señalan las pautas principales para determinar la orientación de nuestra producción. Reconocemos también la necesidad de contar con industrias de exportación viables que suministren divisas para comprax nuestras herramientas $y$ materias primas, aunque, en último análisis, nuestra intención fundamental es 


\section{Documentos}

garantizar al pueblo la satisfacción cle sus necesidacles baisicas, por cjemplo, encaminándonos hacia la autarquia en la producción de alimentos.

Se señalan estos puntos a su atención y a más de informarlos y ampliar su comprensión como visitantes, esperamos indicarles las direcciones que podrían tomar para coadyuvar a nuestros esfuerzos.

A este respecto, señor Presidentc, debo hacer una pausa para expresar que Jamaica felicita el Banco Interamericano de Desarrollo por sus realizaciones al movilizar recursos financieros para los esfuerzos de la región: más de 5.000 millones de dólares en préstamos para proyectos cuyo costo total pasa de los $16.000 \mathrm{mi}$ llones de dólares, es un meritorio historial del cual bien puede usted enorgullecerse.

Jamaica aplaude la flexibilidad y la sensibilidad social características de la política de préstamos del BLD. Asimismo, el establecimiento de oficinas regio. nales para facilitar la corriente de financiamiento ha sido una innovación útil.

A Jamaica le complace que el Banco Interamericano de Desarrollo, en las políticas que ha seguido y continuará siguiendo, representa un ejemplo imaginativo y cficiente de una cooperación económica fructífcra entre paises desarrollados y' países en desarrollo.

Creemos que se ha ganado, en plena medida, el apoyo $y$ la confianza de los gobiernos de los Estados Unidos de América y del Canadá, y' encomiamos su pedido de nuevos recursos a los Gobemadores de los paises clesarrollados extra* hemisféricos.

Jamaica insta al BID a que siga dando preeminencia al pueblo por sobre los sistemas políticos, económicos y sociales, $\gamma$, en realidad, por sobre todos los otros recursos del proccso de desarrollo. A este respecto instamos al BID a modificar las políticas para aumentar las inversiones en educación y capacitación. El Banco reforzará su eficacia, no sólo en ayudar a los paises cuyo principal recurso es el elemento humano, sino a otros países cuyos vastos recursos físicos requieren un gran esfuerzo humano e imaginativo para encauzarlos en bien del pucblo. El examen de su propia experiencia bien puede poner de manifiesto que la inversión en las cosas es menos productiva que la inversión en las personas. La inversión en los individuos libera el potencial creativo y el espíritu innovador que convierten las cosas en recursos.

Además xecomendamos que el BID considere seriamente el otorgamiento de préstamos para ampliar la existencia de bienes de "cuasicapital" que producen un beneficio inmediato y dirccto en la elevación del nivel de la vida de familia y de la comunidad. Me refiero concretamente al desarralio urbano y físico de la comunidad, incluida la vivienda.

Para poner aún más el acento en la preeminencia del individuo, instamos al BID a reconsiderar las situaciones que excluyen a algunos pueblos del hemisferio del acceso a recunsos financieros de importancia decisiva para el mejoramiento de su bienestar $y$ la movilización de su potencial, con el fin de eliminar las condiciones de pobreza $y$ sufrimiento. En otros ámbitos, Jamaica ha expresado claramente su convicción de que la solidaridad hemisférica debe șustentarse 
en el principio de no discriminación contra los pueblos por razones políticas, culturales y de otra índole. Jamaica condena, por estimarla moralmente errónea, la vinculación de las consideraciones políticas y económicas en la determinación de las políticas de las instituciones financieras hemisféricas e internacionales, negando así el apoyo económico a grupos de pueblos por razbn de sus circunstancias políticas. Estamos convencidos de que las políticas de una institución financiera como el BW no deben distorsionarse por la necesidad de reflejar el punto de vista de una parte en una diferencia entre Estados y que el Banco debe procurar desinteresarse de ellas. Queremos referimos, en especial, a la exclusión del pueblo dé Guyana del acceso a los recursos financieros movilizados por el Banco. Quisiéxamos señalar que a medida que el Banco trata de ampliar las fuentes de recursos, una cantidad mayor de fondos que se encauzarán por los conductos bilaterales bien podrían reorientarse hacia las entidades crediticias multilaterales. Los países excluidos de esos organismos pueden verse obligados a procurarse recursos en el marco de acuerclos bilaterales desfavorables que entrañan la "vinculación" de los préstamos y el riesgo de ingerencia e influencia de orientación política en sus asuntos internos.

Jamaica insta al Banco a considerar seriamente la situación de Estados que no tienen todavía una total independencia politica y que, por no tener acceso a los organismos crediticios internacionales, se ven impedidos de avanzar hacia la independencia económica. La inquietud por el futuro de todos los pueblos del hemisferio debe impulsar al Banco a estudiar las posibilidades de ampliar las corrientes de recursos financieros hacia las Islas de Sotavento y Barlovento, quizá por conducto de las instituciones financieras regionales existentes, como el Banco de Desarrollo del Caribe, y la prestación de apoyo técnico en los esfuerzos de integración económica de la región.

Como político que soy, sé que las consideraciones políticas son importantes. Los economistas nos dirán que los sistemas económicos son importantes; otros destacarán la importancia de otros aspectos del desarrollo. He puesto el acento en los pueblos porque ellos suelen ser el elemento olvidado en las deliberaciones de los órganos que deciden las políticas que afectan a su futuro. Sólo devolviendo al pueblo el lugar que legítimamente le corresponde podemos estar seguros de que las políticas de desarrollo de las instituciones que hemos creado a ese objeto, realmente aranzan, de manera eficaz e inequivoca, en la promoción de un futuro más próspero para la humanidad.

Por consiguiente, debemos procurar que el desarrollo se ocupe del "pueblo" más que de las "cosas". Debemos cultivar las aptitudes humanas que, aplicadas con espiritu de autonomia, crearán naciones que puedan forjar las cosas que necesiten.

De este modo cada nación contribuirá a la capacidad de todos los páses para cristalizar esos anhelos de justicia y proceso en libertad que, en último análisis, justifican la existencia humana. 